\title{
Introducing CLIPP \\ College Library Information on Policy and Practice
}

W

hen it was initiated in 1980, the College Libraries Information Packet (CLIP) Notes program was designed to provide "college and small university libraries with stateof-the-art reviews and current documentation on library practices and procedures of relevance to them." ${ }^{1}$ Each publication provided a short literature review and the results of a survey completed by 200 or so program participants, but the real value of the work was in the collection of policy statements and procedure descriptions created by other college and small university libraries. By offering useful documents on timely issues, CLIP Notes saved librarians time and money.

With such information now available via a quick Web search or electronic list post, we, the members of the College Libraries Section CLIP Notes Committee, had to ask ourselves: Had the series outlived its usefulness?

After a year of discussion and debate, we concluded that the format of CLIP Notes, with its focus on documentation over assessment, is quickly becoming as irrelevant as CD-ROMs. However, we also became convinced that the function of the CLIP Notes program is still relevant. In a 1985 article entitled "What is a CLIP Note?" P. Grady Morein wrote:

The function of the CLIP Notes program is to share information among smaller academic libraries as a means of facilitating decision making and improving performance. The basic premise underlying the program is that libraries throughout the nation are facing numerous challenges due to changing environments and that many of these libraries can benefit by knowing how similar institutions have resolved certain problems. ${ }^{2}$

Although much has changed in the last 30 years, this basic premise still holds. Libraries are still grappling with common challenges, and there is much to be gained by sharing information. Knowing how similar institutions have handled certain issues and problems is as important today as ever; none of us wants to spend valuable resources reinventing the wheel.

Therefore, together with the Executive Committee of ACRL's College Library Section, we are pleased to announce the launch of a new monographic series called CLIPP: College Library Information on Policy and Practice. The new publication will differ from its predecessor in three important ways:

- The Title. Whereas "packet" implied a small collection of physical documents; the new publication will be much more robust both in terms of content and format. Our sincere apologies to catalogers.

- The Scope. Each CLIPP publication will be a multifaceted examination of a significant issue college libraries face and will include a complete review of the literature and appropriately complex data analysis. The goal is to provide librarians with both context for and quantitative analysis of important library trends. Due to this change in the scope of

Erin T. Smith is chair of the CLS ClipNotes Committee and is electronic resources and systems librarian at Westminster College's McGill Library, smithet@ westminster.edu

(c) 2011 Erin T. Smith 
work, content creators will be called authors, not "compilers" as they were for the previous series. CLIPP will also retain the idea of a documents section by offering "best practices" policies and procedure documents from institutions doing remarkable and innovative work.

- The Survey Pool. The new publication will require authors to survey the entire United States population of college and small university libraries. This will allow authors to generate statistically significant results that are generalizable to all college and small university libraries, rather than the limited claims that could be made by CLIP Note compilers (i.e., " $\mathrm{x} \%$ of the survey respondents" have adopted the practice under consideration). For a complete description of how we used the Carnegie Classification System to define colleges and small universities, go to the CLIPP Web site at www.ala.org/ala/mgrps /divs/acrl/aboutacrl/directoryofleadership /sections/cls/collpubs/clipp.cfm.

\section{Call for papers}

Any librarian at a college or small university can submit a proposal to the CLIPP committee. Any library trend or subject of interest is a potential topic. Possible topics include user-driven libraries, library exhibits, licensing, staff development, liaison programs, and the place of the library in campus organizational structures. For a full description of the submission and publication process, see the CLIPP Web site.

Once the committee has approved a proposal via the process outlined on the Web site, college and small university libraries across the country will receive an e-mail with CLIPP in the subject line. If you are a library administrator, please take the time to complete these surveys.

We know your time is valuable; the reason the CLIP Note series was so successful is that it saved librarians' time by providing real solutions. But the series won't work without your participation. A few minutes of work on completing a survey could save you hours of work when drafting a new policy or procedure!
In 1985, Morein described CLIP Notes as "one of the most useful of ACRL's college library programs" because it "focuse[d] directly on the needs of college and small university libraries, providing concrete tools for addressing specific problems and concerns."

We believe that the next generation of this series will be just as useful to college and small university libraries today as CLIP Notes were in the past. The expanded literature review and survey analysis with statistical significance represent time-consuming work that requires specific expertise and significant time commitments, things that the librarian seeking to discover practices of similar libraries doesn't always have. But the success of this publication is dependent upon wider involvement, both of CLIPP authors and survey respondents. If you would like to develop a CLIPP, please send your idea to any of the committee members listed below.

CLIPP Committee Members: Erin T. Smith (chair), Westminster College, smithet@ westminster.edu; Jennie E. Callas, Randolph-Macon College, jcallas@rmc.edu; Jane P. Currie, Loyola University Chicago, jcurrie@luc.edu; Melinda K. Dermody, Syracuse University, mdermo01@syr.edu; Nancy E. Frazier, Bucknell University, nef007 @bucknell.edu; Elizabeth Hoppe, Union College, beth.hoppe@gmail.com; Claudia Ruediger, Southeast Missouri State University, cruediger@semo.edu; Paul B. Drake, University of Guam, pdrake@uguam.uog.edu; Mark McKinley Sanders, East Carolina University, sandersm@ecu.edu.

The committee would like to thank Jill Gremmels (CLIP Note chair 2009-11) for her vision and her work in bringing CLIPP to life. We would also like to thank Kathryn Deiss, our ACRL staff liaison, for her encouragement and direction throughout this process.

\section{Notes}

1. P. G. Morein, "What is a CLIP Note?" College \& Research Libraries News 46 (May 1985): 226.

2. Ibid., 226.

3. Ibid., $228 \pi$ 